\title{
Empirical research about effect of economic growth on employment based on Hangzhou city
}

\author{
Rong Li \\ Zhejiang Business College, Hangzhou 310053, China Irlr1212@sina.com
}

Keywords: economic growth, industrial structure, employment elasticity coefficient, Hangzhou

\begin{abstract}
It is of great forward-looking significance for rational allocation of human resources to understand the impact of economic growth on employment. From two different angles, empirical research about effect of economic growth on employment based on Hangzhou city in recent years is conducted, and results show that: from perspective of economic development level, with the constant improvement of economic level, the trend that labor force is gradually transferred to teriary industry is increasingly prominent; From perspective of economic speed in recent years, effect of Hangzhou economic growth on employment of teriary industry is most obvious, and employment elasticity coefficient of teriary industry is much higher than that of other two industries. At present development of Hangzhou employment structure still lags behind development of industrial structure, and this state provides a huge space for teriary industry to absorb employment.
\end{abstract}

\section{Introduction}

There is a certain correlation between economic growth and employment ${ }^{[1-3]}$. Previous studies show that economic growth firstly results into change of industrial structure, and evolution of industrial structure can result into change of employment structure. Two economists have found that with the development of economy, national income and employment proportion of primary industry gradually declined, while national income and employment proportion of second and teriary industry gradually rised. Other empirical studies show that transformation of industrial structure in developing countries generally is ahead of employment structure. The conclusion is of great guiding significance for transformation of employment structure in developing countries.

In current situation that economic structure is to be adjusted ${ }^{[4]}$, and economic growth mode is to be transformed, employment will be faced with more complex difficulties and challenges. On one hand, economic downward pressure is bigger, and under complicated situation all over the world it is more difficult to adjust economic structure and promote economic growth; Every year, on the other hand, number of college graduates breakthrough new high unceasingly, social employment pressure is increasing year by year, and it is more difficult to achieve full employment. Therefore, it is necessary to understand relationship between economic growth and employment, to find effect of economic growth on employment, grasp and deal with relationship between these two, which is of important practical significance to guide college graduates employment direction, optimize allocation of human resources, and promote coordinated development of economy and society, and which is also an important subject in front of government. So this paper is focused on effect of economic growth on employment based on Hangzhou city ${ }^{[5,6]}$.

\section{Change of Hangzhou industry structure and employment structure}

\subsection{Change of Hangzhou industry structure.}

In recent years GDP proportion of three different industries is shown in figure 1 . In this paper, data are all from Hangzhou statistical yearbook in recent years. 


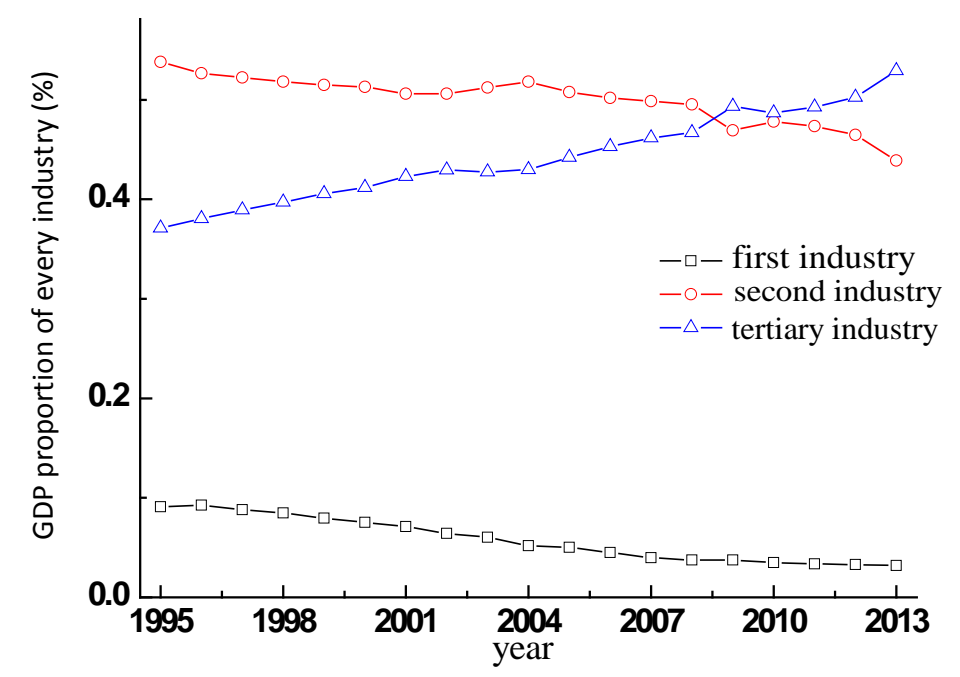

Fig.1 output proportion of every industry in recent years

Hangzhou GDP proportion of primary industry decreased from $17.65 \%$ in 1985 to $3.2 \%$ in 2013, GDP proportion of second industry decreased from $57.6 \%$ in 1985 to $43.9 \%$ in 2013, while GDP production of tertiary industry rapidly rised, almost one percent a year on average. In 2009 GDP proportion of Hangzhou tertiary industry firstly catched up with second industry, and achieved more than half of total economy as a whole. Hangzhou economic structure is also changed from "231" to "321". Contribution rate of tertiary industry to economic growth rised year by year, and tertiary industry become the most important driving force to economic growth.

\subsection{Change of Hangzhou employment structure.}

In recent years employment proportion of three different industries is shown in figure 2. Among them, firstly employment of different industry is respectively divided by total employment, which is equal to employment proportion of different industry.

Hangzhou employment proportion of primary industry decreased from 34\% in 1985 to 10.8\% in 2013, employment proportion of second industry rised from 37.2\% in 1985 to $44.8 \%$ in 2013, and also employment production of tertiary industry rapidly rised, almost one percent a year on average, in 2013 is almost equal to employment proportion of second industry.

\section{Empirical research about effect of economic growth on employment}

The above analysis shows that tertiary industry has been a pivotal position in Hangzhou economy, thus this article focuses on effect of economic growth on employment of tertiary industry.

3.1 Research on relation between economy level and employment proportion of Tertiary industry.

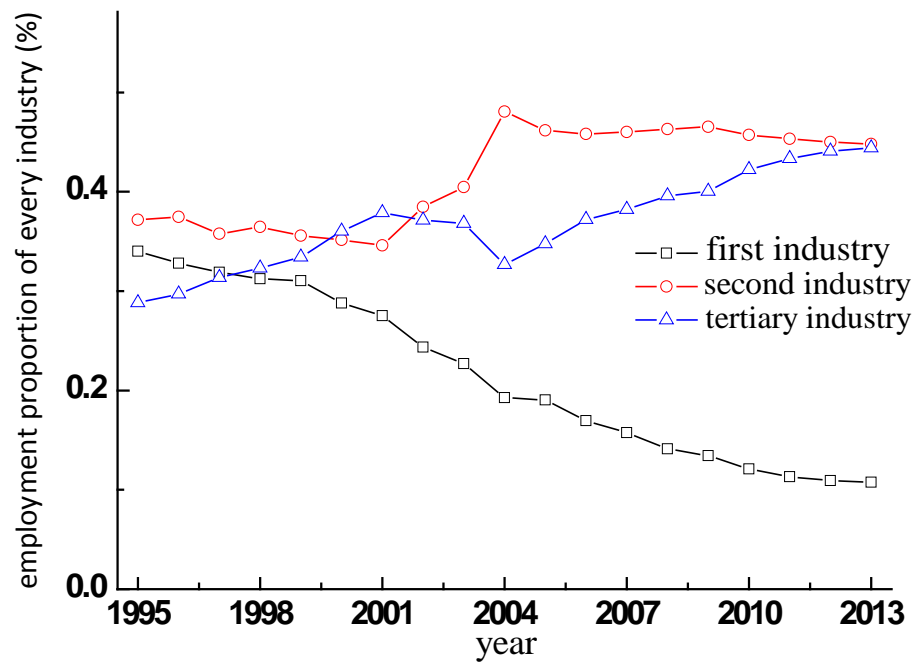

Fig.2 The proportion of employment about every industry in recent years 
Hangzhou per capita GDP is equal to total GDP divided by tresident population in Hangzhou, and all data are from Hangzhou statistical yearbook. Hangzhou per capita GDP and employment proportion of tertiary industry in recent years are shown in table 1.

Tab.1 Per capita GDP and employment proportion of teriary industry in recent years

\begin{tabular}{ccc}
\hline year & $\begin{array}{c}\text { per capita GDP } \\
\text { (yuan) }\end{array}$ & $\begin{array}{c}\text { Employment proportion of } \\
\text { tertiary industry }(\%)\end{array}$ \\
\hline 1995 & 18093.73 & 28.82 \\
1996 & 21455.69 & 29.73 \\
1997 & 24654.96 & 31.38 \\
1998 & 27014.60 & 32.30 \\
1999 & 29381.31 & 33.42 \\
2000 & 22342.00 & 36.06 \\
2001 & 24923.00 & 37.90 \\
2002 & 27980.00 & 37.14 \\
2003 & 32667.00 & 36.82 \\
2004 & 38690.00 & 32.67 \\
2005 & 44871.00 & 34.78 \\
2006 & 51908.00 & 37.22 \\
2007 & 61315.00 & 38.24 \\
2008 & 70948.00 & 39.60 \\
2009 & 74761.00 & 40.05 \\
2010 & 86691.00 & 42.21 \\
2011 & 80478.00 & 42.21 \\
2012 & 88985.00 & 44.08 \\
2013 & 94566.00 & 44.41 \\
\hline
\end{tabular}

Correlation coefficient between these two indicators is as high as 0.88 , showing that there is high correlation between them. Then, regression analysis between these two indicators is considered. According to effect of economic growth on employment, economic growth is selected as independent variable, and employment proportion is selected as dependent variable, and regression result is shown in figure 3.

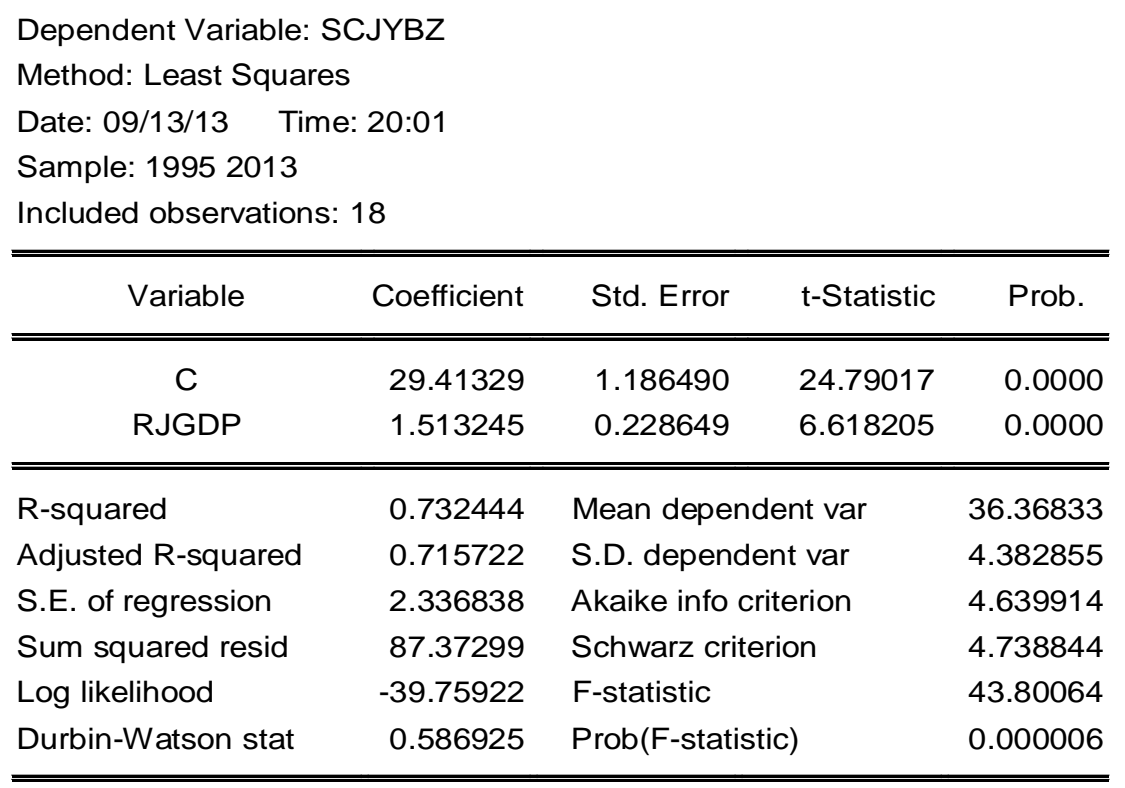

Fig.3 Regression analysis diagram

Fitting results show that:

(1) Regression coefficient of dependent is 1.513, t-statistic of regression coefficient is 6.618, and significance level is 0.0000 which is lower than 0.01 , so regression coefficient is significant. Further 
more t-statistic of intercept $\mathrm{C}$ is 29.413 , significance level is 0.000 which is lower than 0.01 , and regression coefficient of intercept $\mathrm{C}$ is significant too.

(2) Fitting effect of regression equation is 0.732 , adjusted fitting effect is 0.715 , and S.E. of regression is 2.336. F statistic value of regression equation model is 43.8 , due to significance level is $0.0000<0.01$, regression equation is significant.

Regression equation is obtained: employment proportion of Hangzhou tertiary industry $=29.413+$ 1.513 x per capita GDP.

If per capita GDP of Hangzhou is increased 1 (ten thousand yuan), employment proportion of teriary industry is raised by $1.5 \%$. With the development of Hangzhou economy, employment proportion of tertiary industry will rise more and more, and tertiary industry has become pillar industry in Hangzhou, which is also accord with general law of economic development.

\subsection{Driving effect of economic growth on employment based on Hangzhou city}

Employment elastic coefficient refers to percentage that employment proportion will be changed if economic growth is raised one percent. Formula of employment elastic coefficient is that: employment elasticity coefficient = rate of national employment growth $/$ rate of GDP growth. Higher employment elastic coefficient is, more significant effect of economic growth on employment is.

\subsubsection{Data preparation}

Important data of Hangzhou such as GDP and employment of every industry each year are all from Hangzhou statistical yearbook in recent years..

\subsubsection{Employment elastic coefficient of every industry}

Formula of employment elastic coefficient is that

$$
E=d_{L /} d_{Y}
$$

Here, $d_{L}$ is growth rate of employment, $d_{Y}$ is growth rate of GDP. Employment elastic coefficient of different industry is shown in table 3.

Tab.3 Employment elastic coefficient of every industry in recent years

\begin{tabular}{ccccc}
\hline year & $\begin{array}{c}\text { Employment elastic } \\
\text { coefficient }\end{array}$ & $\begin{array}{c}\text { primary } \\
\text { industry }\end{array}$ & $\begin{array}{c}\text { Second } \\
\text { industry }\end{array}$ & $\begin{array}{c}\text { tertiary } \\
\text { industry }\end{array}$ \\
\hline 1996 & 0.02 & -0.15 & 0.07 & 0.16 \\
1997 & -0.04 & -0.38 & -0.37 & 0.29 \\
1998 & -0.01 & -0.40 & 0.21 & 0.24 \\
1999 & -0.09 & -0.91 & -0.44 & 0.27 \\
2000 & -0.17 & -1.41 & -0.26 & 0.38 \\
2001 & 0.09 & -0.45 & -0.04 & 0.39 \\
2002 & 0.50 & -1.90 & 1.38 & 0.30 \\
2003 & 0.12 & -0.47 & 0.39 & 0.07 \\
2004 & 0.28 & -2.24 & 1.15 & -0.27 \\
2005 & 0.05 & -0.04 & -0.24 & 0.38 \\
2006 & 0.38 & -1.15 & 0.36 & 0.70 \\
2007 & 0.21 & -0.62 & 0.25 & 0.32 \\
2008 & 0.41 & -0.44 & 0.46 & 0.58 \\
2009 & 0.80 & -0.01 & 8.95 & 0.51 \\
2010 & 0.29 & -0.60 & 0.16 & 0.68 \\
2011 & 0.10 & -0.34 & 0.06 & 0.24 \\
2012 & 0.09 & -0.31 & 0.03 & 0.21 \\
\hline
\end{tabular}

Due to severe fluctuation of employment elastic coefficient each year, average employment elasticity coefficient is used to eliminate numerical variation. According to formula (1), at first growth rate of total GDP and employment is calculated by using data in table 3 from 1996 to 2013, then we solve fiftheen root of these growth rate, which respectively is average growth rate of GDP, average growth rate of employment and average employment elasticity coefficient. Through calculation, total employment elasticity coefficient of Hangzhou $=0.025 / 0.147=0.176$. Among them, employment elasticity coefficient of primary industry is -0.524 , employment elasticity coefficient of 
second industry is 0.275 , and employment elasticity coefficient of tertiary industry is 0.313 . The teriary industry gradually becomes main power to boost employment growth.

\section{Conclusion}

In recent years rapid development of teriary industry, which is accounted for nearly half of whole economy and whose proportion is more than that of second industry, has a pivotal position in Hangzhou economy.

(1) This paper discussed effect of economic growth on employment from two different points of view, one is from economic development level, the paper analyzed relationship between per capita GDP and employment proportion; the other is from perspective of economic growth, this paper analyzed driving effect of economic growth on employment growth.

(2) In recent years, effect of Hangzhou economic growth on employment of teriary industry is remarkable. If per capita GDP of Hangzhou is increased 1 (ten thousand yuan), employment proportion of teriary industry is raised by $1.5 \%$., which shows that with the development of economy, employment proportion of teriary industry is higher and higher. Average employment elasticity coefficient of teriary industry in recent years is 0.313 , ranked first in three industries, nearly 4 percent higher than that of second industry, which shows that driving effect of Hangzhou economic growth on employment of tertiary industry is ominent. Teriary industry has become main battlefield to absorb employment, and results pointed out direction of human resource allocation for the future.

(3) Development of Hangzhou employment structure lags behind development of industrial structure. It can be seen that although in 2013 output proportion of Hangzhou tertiary industry reaches $52.9 \%$, but employment proportion is only $44.4 \%$, which is behind output proportion nearly $8.5 \%$, but it also provides a huge space for employment development of teriary industry.

\section{References}

[1] H.Chenery. Industrialization and growth: a comparative study [M]. Shanghai: Shanghai Sanlian bookstore.

[2] Liu xianmei. Study on relationship between industrial structure and employment structure [J]. economic forum, 2010, (4): 133-135.

[3] Chen dahong. Research on correlation of China's industry structure and employment structure [J]. Industrial \& Science Tribune, 2007, 03:24-26.

[4] Shi xuelei. Research on adjustment of industrial structure based on view of employment [D]. Shanghai: Fudan University, 2010.

[5] Hong guangyu. In "labor shortage", Hangzhou economic is transformed and upgraded step by step. Hangzhou daily, 2014-02-14.

[6] Lu mingxin. Research on coordinated growth of employment and economy in Hangzhou [J]. Hangzhou research, 2013, (3). 